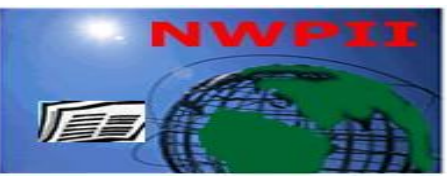

American Journal of Biomedical Sciences

ISSN: 1937-9080

nwpii.com/ajbms

\title{
Triacsin C, a Fatty Acyl CoA Synthetase Inhibitor, Improves Cardiac Performance Following Global Ischemia
}

\author{
Nina Blakeman', Qian Chen², Jasmine Tolson'², Brian Rueter ${ }^{2}$, Brian Diaz $^{2}$, Brendan Casey ${ }^{2}$, \\ Lindon H. Young ${ }^{2}$, Margaret T. Weis ${ }^{1 *}$
}

\author{
${ }^{1}$ Department of Biomedical Sciences, Vascular Drug Research Center, School of Pharmacy, Texas Tech University, \\ Health Sciences Center, Amarillo, Texas, USA \\ ${ }^{2}$ Department of Pathology, Microbiology, Immunology and Forensic Medicine, Philadelphia College of Osteopathic \\ Medicine, Philadelphia, Pennsylvania, USA \\ Corresponding Author: \\ Margaret T. Weis, Ph.D. \\ Department of Biomedical Sciences \\ School of Pharmacy \\ Texas Tech University Health Sciences Center \\ 1300 Coulter Drive, Room 400 \\ Amarillo, Texas 79106 \\ USA \\ 806.356.4015, ext. 281 (voice) \\ 806.356 .4643 (fax) \\ Margaret.weis@ttuhsc.edu \\ Nina Blakeman and Qian Chen both contributed equal effort and are co-first authors for this manuscript
}

Received: 21 June 2012; | Revised: 24 June 2012; | Accepted: 29 June 2012

\begin{abstract}
The role of fatty acyl CoA synthetase (FACS) in ischemia/reperfusion (I/R) injury has not been well established. Our earlier studies showed that triacsin C, a selective FACS inhibitor, decreases endothelial nitric oxide synthase (eNOS) palmitoylation and increases nitric oxide (NO) in cultured human coronary endothelial cells. In the present study, we tested the hypothesis that triacsin $\mathrm{C}$ would reduce infarct size and improve post-reperfusion cardiac function by increasing vascular NO. In isolated rat hearts, triacsin $\mathrm{C}$, given during the first 5 minutes of reperfusion, significantly reduced infarct size and attenuated cardiac dysfunction during reperfusion. $N^{G}$-nitro-L-arginine methyl ester (L-NAME, a non-selective NOS inhibitor, $50 \mu \mathrm{M}$ ) completely abolished the protective effects of triacsin $\mathrm{C}$. In the ischemic hind limb model, triacsin $\mathrm{C}$ significantly increased intravascular NO concentration during reperfusion, an effect that was blocked by LNAME or S-methyl-L-thiocitrulline (SMTC, a selective neuronal NOS inhibitor), but not by $1400 \mathrm{~W}$ (a highly selective iNOS inhibitor). Lastly, triacsin C significantly reduced L-NAME induced leukocyte rolling, adhesion, and transmigration in rat mesenteric circulation, as measured by intravital microscopy. In summary, this study provides novel evidence showing that triacsin $\mathrm{C}$ reduces myocardial infarct size, attenuates loss of post-reperfusion cardiac function, increases intravascular NO concentration and inhibits leukocyte recruitment. These pharmacologic properties suggest that triacsin $\mathrm{C}$ may be useful as an adjunct to
\end{abstract}


standard thrombolytic/anti-platelet pharmacotherapy of myocardial infarction.

Keywords: fatty acyl CoA synthetase, triacsin C, myocardial ischemia/reperfusion, cardiac function, infarct size, nitric oxide, inflammation

\section{Introduction}

Ischemic heart disease, including myocardial infarction, accounts for more than $18 \%$ of all deaths in the U.S. Although the survival rates for ischemic heart disease have risen dramatically in the past 20 years, the mortality rate for a first myocardial infarction remains over $30 \%$ [1]. Current drug therapy for ischemic injury has centered on supportive care, with few available drugs (such as tPA) to limit I/R damage directly.

Beyond tissue damage from ischemia alone, reperfusion exacerbates endothelial dysfunction and initiates inflammation [2-4]. It has been suggested that endothelial-derived nitric oxide (NO) release and bioavailability is reduced within 5 min of reperfusion [4]. Thereafter, leukocyte recruitment and infiltration extend tissue/organ injury, with neutrophils being the most abundant leukocyte type [5]. When blood flow slows or stops, factors that mediate neutrophil recruitment, such as P-selectin and intercellular adhesion molecule-1 (I-CAM-1), are translocated to the luminal face of the vascular endothelium [6,7]. In experimental myocardial infarction, neutrophil trapping in the microvasculature is observed within the first hour of reperfusion [8]. Leukocyte-induced microvascular permeability leads to tissue edema with subsequent changes in microvascular hemodynamics, tissue oxygenation, and, ultimately, organ failure [9].

Endothelial-derived NO, produced constitutively by eNOS, is crucial to the maintenance of normal vasodilatory, antiinflammatory, and anti-thrombotic functions [4]. Impaired endothelial-derived NO bioavailability is the hallmark of vascular endothelial dysfunction, which occurs during normal aging [2] as well as in $\mathrm{I} / \mathrm{R}$ injury, hypertension, diabetes, atherosclerosis [10-12].

It is well established that competitive inhibition of eNOS with L-NAME can induce inflammatory responses [13,14]. In contrast, experimental conditions which increase endothelial NO synthesis decrease endothelial surface P-selectin and ICAM-1 expression [15] consequently limiting infarct extension [16].

On a molecular level, eNOS function depends on the availability of cofactors such as tetrahydrobiopterin. In addition, the catalytic activity and subcellular localization of eNOS are governed by a complex series of interactions with other proteins [17-24], phosphorylation [25,26], and palmitoylation [24,27-29]. eNOS is palmitoylated at residues $\mathrm{Cys}^{15}$ and $\mathrm{Cys}^{26}$ [30], facilitating translocation and interaction with the caveolin-1 membrane protein [27,31,32] mediating eNOS inactivation.

Triacsin $\mathrm{C}$ is a FACS inhibitor derived from Streptomyces aurofaciens [33]. Earlier, we reported that triacsin $\mathrm{C}$ decreases eNOS palmitoylation in human coronary endothelial cells, increases 24 hour media nitrite accumulation, and enhances agonist stimulated NO synthesis and vascular relaxation in rat aorta [34], without changing eicosanoid release [35]. These effects on NO synthesis and endothelial function strongly suggested that triacsin $\mathrm{C}$ might be beneficial in I/R injury.

In this study, we hypothesized that administration of triacsin $\mathrm{C}$ would limit infarct size and improve post-reperfusion cardiac function, and that these effects would be associated with increased bioavailability of NO in the post-reperfusion period and decreased leukocyte-endothelial interactions.

\section{Methods}

Animals: The Institutional Animal Care and Use Committees of Texas Tech University Health Sciences Center or of the Philadelphia College of Osteopathic Medicine approved all animal protocols performed in this study.

Global Cardiac Ischemia: Hearts were rapidly excised from heparinized (1000 U i.p.) 
male Sprague-Dawley rats (275-325 g; Ace Animals, Boyertown, PA) under pentobarbital sodium $(60 \mathrm{mg} / \mathrm{kg})$ anesthesia. The isolated hearts were perfused via an aortic cannula and immersed in a water-jacketed reservoir containing $160 \mathrm{ml}$ of Krebs' Hensleit buffer (KHB; in $\mathrm{mmol} / \mathrm{l}$ : 17.0 dextrose, $120.0 \mathrm{NaCl}, 25.0 \mathrm{NaHCO}_{3}, 2.5 \mathrm{CaCl}_{2}$, 0.5 EDTA, $5.9 \mathrm{KCl}$, and $1.2 \mathrm{MgCl}_{2}$ ) maintained at $37^{\circ} \mathrm{C}$ and equilibrated with $95 \% \quad \mathrm{O}_{2}-5 \% \quad \mathrm{CO}_{2}$ to maintain a $\mathrm{pH}$ of 7.3-7.4. Perfusion pressure was maintained at $80 \mathrm{mmHg}$ as previously described [36].

Coronary flow was monitored by a T106 flowmeter (Transonic Systems, Inc., Ithaca, NY). Left ventricular developed pressure (LVDP) and the maximal or minimal rate of $\mathrm{LVDP}\left(\mathrm{dP} / \mathrm{dt}_{\max }\right.$ or $\mathrm{dP} / \mathrm{dt}_{\min }$ ) were monitored using a SPR-524 pressure transducer (Millar Instruments, Inc., Houston, TX) positioned in the left ventricular cavity and recorded using a Powerlab Station acquisition system (ADInstruments, Grand Junction, CO).

After establishing baseline coronary flow, LVDP, $\mathrm{dP} / \mathrm{dt}_{\min }$ and $\mathrm{dP} / \mathrm{dt}_{\max }$, ischemia was induced for $30 \mathrm{~min}$ by reducing the flow of Krebs' buffer to zero. Commencing at reperfusion, performance parameters were recorded every 5 min for 45 min post-reperfusion.

Reperfusion was initiated by infusion of $5 \mathrm{ml}$ of autologous plasma collected from the abdominal aorta immediately prior to cardiac excision (control hearts) or autologous plasma containing triacsin $\mathrm{C}(5 \mu \mathrm{M})$ at a rate of $1 \mathrm{ml} / \mathrm{min}$ for $5 \mathrm{~min}$. [36]. At the end of the experiment, the infarct area was visualized by treatment with $1 \%$ 2,3,5- triphenyltetrazolium chloride (TTC).

Intravascular NO measurement: The effect of triacsin $\mathrm{C}$ on vascular NO synthesis was measured in the rat hind limb $\mathrm{I} / \mathrm{R}$ model. Anesthesia was induced in heparinized (1000 U i.p.) male Sprague-Dawley rats (275 to $325 \mathrm{~g}$, Charles River, Raleigh, NC) with $\mathrm{Na}$ pentobarbital, $60 \mathrm{mg} / \mathrm{kg}$, and maintained with 30 $\mathrm{mg} / \mathrm{kg}$ sodium pentobarbital, as needed. A catheter was placed in the tail vein for administration of drugs or vehicle. Both femoral arteries and veins were exteriorized and NO microsensors $(100 \mu \mathrm{m}, \quad$ World Precision Instruments (WPI) Inc., Sarasota, FL) were inserted into both femoral veins via 24 gauge catheters as previously described [37,38]. Following a 15-minute baseline measurement, one femoral artery/vein was clamped for 20 minutes while the contralateral limb served as the sham control. After release of the clamp, intravascular NO concentration was followed for an additional 45 minutes. Prior to baseline measurement, experimental animals received a single dose of triacsin C $(100 \mu \mathrm{g} / \mathrm{kg})$ with or without L-NAME (non-selective NOS inhibitor, $30 \mathrm{mg} / \mathrm{kg}$ ), $1400 \mathrm{~W}$ (highly selective iNOS inhibitor, $10 \mu \mathrm{g} / \mathrm{kg}$ ), or SMTC (a selective nNOS inhibitor, $1.2 \mathrm{mg} / \mathrm{kg}$ ) while the controls were treated with vehicle $(5 \%$ DMSO in normal saline). The NO levels during reperfusion were expressed as the relative difference of NO between I/R and sham limb as previously described (38). This technology allows for the real-time measurement of $\mathrm{NO}$ in blood [39].

Leukocyte recruitment: The effect of triacsin $\mathrm{C}$ on leukocyte rolling, adhesion and extravasation were evaluated in the rat mesenteric vasculature. Briefly, male Sprague Dawley rats (275-325 g; Ace Animals, Boyertown, PA) were anesthetized with $60 \mathrm{mg} / \mathrm{kg}$ of sodium pentobarbital (i.p.) and maintained with $30 \mathrm{mg} / \mathrm{kg}$ of sodium pentobarbital as needed. Arterial pressure was measured by a cannula placed in the carotid artery and connected to a BP-1 Pressure Monitor via a BP1 blood pressure transducer (WPI, Sarasota, FL).

A loop of the iliac mesentery was exteriorized and positioned in a Plexiglas chamber for visualization using a Nikon Eclipse microscope (Nikon Co., Japan). Leukocyte-endothelial interactions were continuously monitored when superfusion of with Krebs-Hensleit buffer (KHB; $114 \mathrm{mM} \mathrm{NaCl}, 4.7 \mathrm{mM} \mathrm{KCl}, 1.2 \mathrm{mM} \mathrm{KH}_{2} \mathrm{PO}_{4} 1.2$ $\mathrm{mM} \mathrm{MgSO}_{4}, 2.5 \mathrm{mM} \mathrm{CaCl}_{2}, 25 \mathrm{mM} \mathrm{NaHCO}_{3}, 5.5$ $\mathrm{mM}$ glucose, equilibrated with $95 \% \quad \mathrm{~N}_{2} / 5 \% \mathrm{CO}_{2}$ ) containing $50 \mu \mathrm{M} \quad$ L-NAME (sub-maximal concentration) [13], with or without $5 \mu \mathrm{M}$ triacsin C. Non-branched post-capillary venules (mean diameter $20 \pm 0.3 \mu \mathrm{m})$ were selected for observation. The image was captured on twominute high-resolution video recordings made at 30 minutes intervals. The numbers of rolling, adherent and transmigrating leukocytes were 
determined during playback analysis of the recorded images.

Leukocytes were considered to be rolling if they were moving at a velocity substantially slower than that of red blood cells. Leukocytes were judged to be adherent if they remained firmly attached to the vascular endothelium for $>30$ seconds. Extravasated leukocytes were counted in the tissue area adjacent to the post-capillary venules and normalized with respect to perivascular area. At the end of the experiment, the venule and surrounding tissues were removed, fixed and stained with hematoxylin and eosin (H\&E) for enumeration of adherent and extravasated neutrophils.

Materials: Triacsin C and L-NAME were purchased from Sigma Chemical Company, St. Louis MO. 1400W and SMTC were purchased from Cayman Chemicals, Ann Arbor MI. All other chemicals were of the highest grade available.

Statistical Analysis: Data were analyzed by 1 or 2 way analysis of variance, as appropriate. All statistical analyses were conducted using the PRISM 5.0b software package. Probability values of $<0.05$ were considered statistically significant.

\section{Results}

Triacsin $C$ and infarct size: In the global ischemia model, the whole heart is at risk. Infarct size was estimated by measuring the tissue not stained by TTC and comparing that to the total of the stained plus unstained tissue. Figure 1A shows representative cross-sections of hearts following global ischemia and reperfusion in control and triacsin $\mathrm{C}$ treated groups. It is noteworthy that, in the control hearts, infarction is most apparent in the sub-epicardial region, and is continuous throughout the circumference of the ventricular wall. In the treated hearts, the infarct is not only smaller, but is discontinuous. As shown in Figure $1 \mathrm{~B}$, treatment with triacsin $\mathrm{C}$ for the first five minutes of reperfusion resulted in an infarct size significantly smaller than all other groups $(p<0.01)$. This effect was abolished by coadministration of L-NAME. The infarct size in hearts treated with L-NAME alone during the first five minutes of reperfusion was significantly greater than in all other groups $(\mathrm{p}<0.05)$.

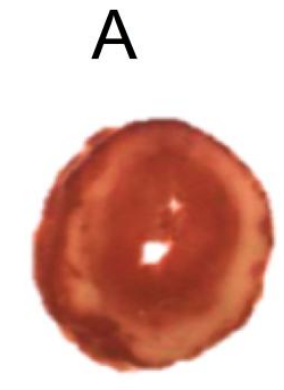

Control

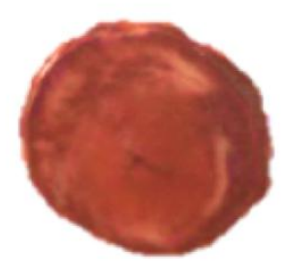

Triacsin C

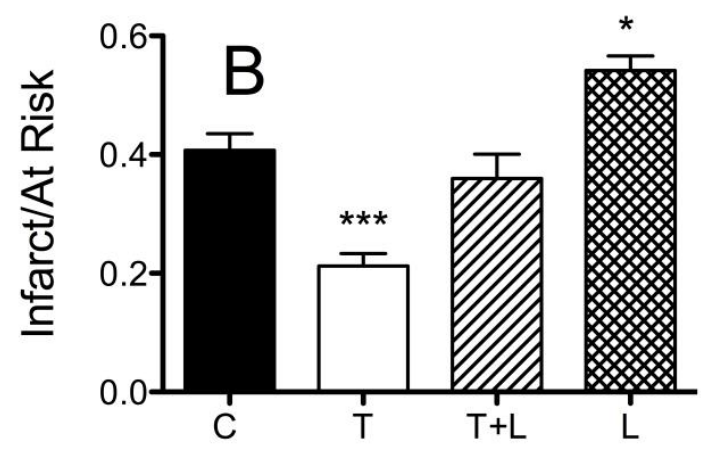

Figure 1. Panel A: Representative photograph of the infarct area in control $(C ; n=6)$ and triacsin $C$ treated hearts $(T ; n=6)$. In the control hearts, the infarct is most apparent in the sub-epicardial region, and is continuous throughout the circumference of the ventricular wall. In the treated hearts, the infarct is not only smaller, but is discontinuous. Panel B. Triacsin $\mathrm{C}$ treatment reduced while L-NAME alone $(\mathrm{L} ; \mathrm{n}=3)$ increased the infarct size as a fraction of the area at risk as compared to all other groups. $*=\mathrm{p}<0.05 ; * * *=$ $\mathrm{p}<0.005$ by one-way ANOVA followed by NewmanKeuls multiple comparison.

Triacsin $C$ and post-reperfusion cardiac function: Triacsin $\mathrm{C}$ treatment $(\mathrm{n}=6)$ for the first five minutes of reperfusion resulted in significantly greater recovery of LVDP, $\mathrm{dP} / \mathrm{dt}_{\max }$, $\mathrm{dP} / \mathrm{dt}_{\text {min }}$ as compared to all other groups (Figure 2 $\mathrm{A}-\mathrm{C}$ ), an effect that was abolished by concurrent treatment with L-NAME $(n=5)$. The pre-ischemic values for these parameters did not differ among the groups. Moreover, by 45 minutes of reperfusion, triacsin $\mathrm{C}$ treated hearts recovered to $77 \pm 5 \%$ of pre-ischemic LVDP, as compared to only $45 \pm 10 \%$ (Control, $n=6$ ), $38 \pm 12 \%$ (Triacsin $\mathrm{C}+\mathrm{L}-\mathrm{NAME}, \mathrm{n}=5$ ) and 39 $\pm 16 \%$ (L-NAME alone, 
$\mathrm{n}=3$ ) of the pre-ischemic value. At 45 minutes reperfusion, the triacsin $\mathrm{C}$ treated hearts recovered $55 \pm 6 \%$ of pre-ischemic $\mathrm{dP} / \mathrm{dt}_{\min }$ and $60 \pm 3 \%$ of pre-ischemic $\mathrm{dP} / \mathrm{dt}_{\max }$. In the remaining three groups recovery of $\mathrm{dP} / \mathrm{dt}_{\min }$ was only $36 \pm 6 \%$ (control), $30 \pm 9 \%$ (triacsin C+L-NAME) and $28 \pm$ 9\% (L-NAME alone) of pre-ischemic values. Recovery of $\mathrm{dP} / \mathrm{dt}_{\max }$ was $31 \pm 6 \%$ (control), $31 \pm$ $11 \%$ (triacsin $\mathrm{C}+\mathrm{L}-\mathrm{NAME}$ ) and $27 \pm 10 \%$ (L-
NAME alone) of pre-ischemic values. The forcerate product at 45 minutes reperfusion was $45.7 \pm$ $5.28 \%$ of baseline in the triacsin $\mathrm{C}$ treated hearts, a value significantly greater than the $24 \pm 4 \%, 25$ $\pm 95 \%$ and $21 \pm 5 \%$ observed in the control, triacsin C+L-NAME and L-NAME hearts, respectively.
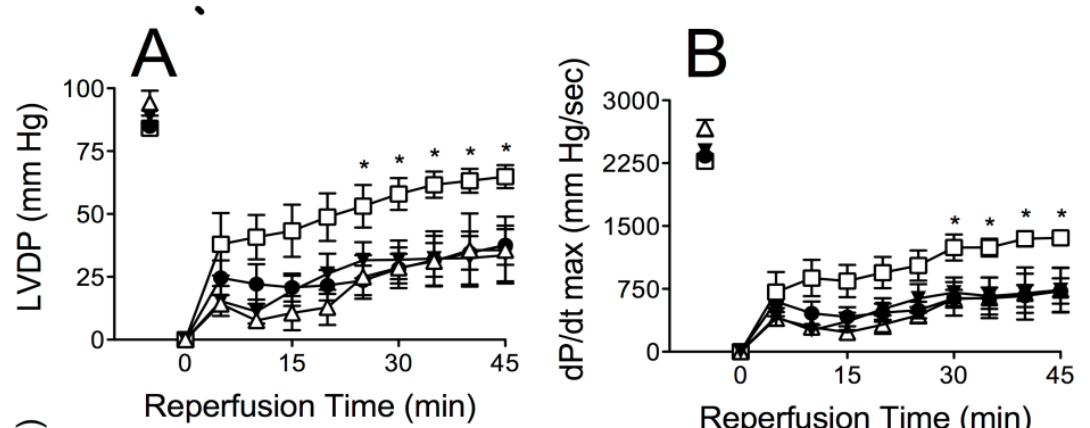

Reperfusion Time (min)
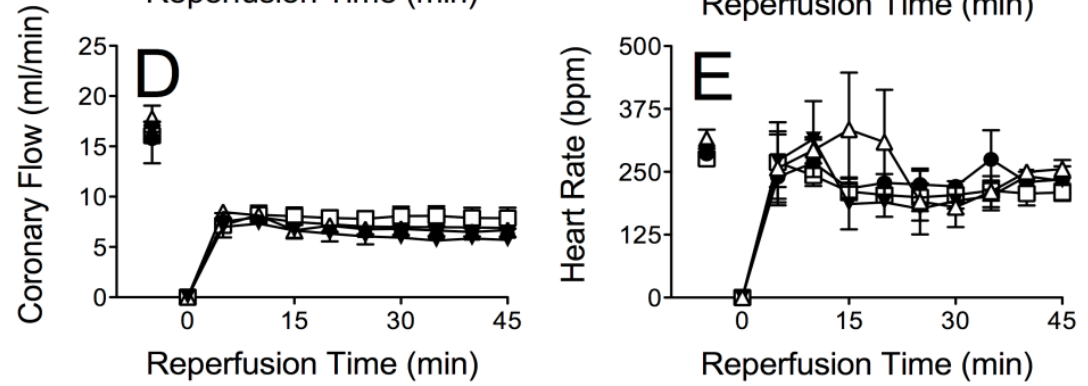

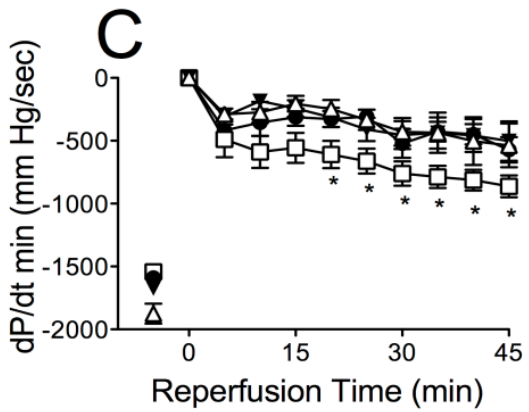

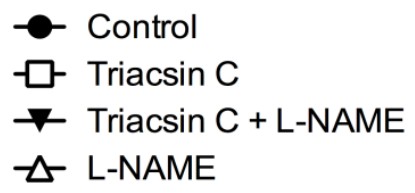

Figure 2. Panel A: Recovery of left ventricular developed pressure (LVDP) was significantly greater in triacsin C treated hearts as compared to all other groups. The overall probability that the results could be accounted for by random variance was $\mathrm{p}=0.0251$ as determined by 2 -way ANOVA for repeated measures. Significant treatment effects at single time points are indicated by * $(\mathrm{p}<0.05)$, as determined by Bonferroni's post-hoc test. Panel B: Recovery of $\mathrm{dP} / \mathrm{dt}_{\max }$ was significantly greater in Triacsin $\mathrm{C}$ treated hearts as compared to all other groups. The overall probability that the results could be accounted for by random variance was $\mathrm{p}=0.0174$ as determined by 2 -way ANOVA for repeated measures. Significant treatment effects at single time points are indicated by $*(\mathrm{p}<0.05)$, as determined by Bonferroni's post-hoc test. Panel C: Recovery of $\mathrm{dP} / \mathrm{dt}_{\min }$ was significantly better in triacsin $\mathrm{C}$ treated hearts as compared to all other groups. The overall probability that the results could be accounted for by random variance was $\mathrm{p}=0.0292$ by 2 -way ANOVA for repeated measures. Significant treatment effects at single time points are indicated by * $(p<0.05)$ as determined by Bonferroni's post-hoc test. Panel D: Triacsin C did not significantly affect reperfusion coronary flow rates. The perfusion pressure was maintained at a constant $80 \mathrm{~mm} \mathrm{Hg}$. The overall probability that the results could be accounted for by random variance was $\mathrm{p}=0.5055$ as determined by 2 -way ANOVA for repeated measures. Panel E: Triacsin C did not significantly affect post-reperfusion heart rates. The overall probability that the results could be accounted for by random variance was $\mathrm{p}=0.7898$ as determined by 2 -way ANOVA for repeated measures.

While reperfusion inotropic and lusitropic functions were significantly better in the triacsin C treated hearts, significant differences in coronary blood flow (Figure 2D) or heart rate (Figure 2E) were not observed. Prior to ischemia, coronary blood flow at $80 \mathrm{~mm} \mathrm{Hg}$ was not different among the four groups. At 45 minutes reperfusion, the flow recovered to $46 \pm 4 \%$ (Control), $49 \pm 4 \%$ (Triacsin $\mathrm{C}$ alone), $34 \pm 2 \%$ (triacsin $\mathrm{C}+\mathrm{L}-\mathrm{NAME}$ ) and $38 \pm 6 \%$ (L-NAME alone) of pre-ischemic 
flow. These values were not significantly different from each other.

The time course of heart rate did not differ among the four experimental groups, either at baseline or during reperfusion (Figure 2E). The flow/beat did not differ among the four groups (data not shown).

Intravascular NO synthesis: Triacsin C treatment significantly increased intravascular NO levels during femoral vascular bed I/R, as shown in Figure 3A. As detailed in methods, this model measures the NO difference between the ischemic (left) and normoxic (right) femoral vascular beds. After taking baseline measurements, ischemia is induced by clamping the left femoral artery for 20 minutes. Reperfusion is initiated by releasing the clamp. A positive number indicates a greater NO signal in the ischemic limb, while a negative number shows a greater $\mathrm{NO}$ signal in the normoxic limb.

Baseline NO signals did not differ between the left and right vascular beds, in either control or triacsin $\mathrm{C}$ treated $(100 \mu \mathrm{g} / \mathrm{kg})$ animals. During ischemia, the average NO levels in the ischemic limbs of both triacsin $\mathrm{C}$ treated and vehicle treated animals decreased relative to the normoxic limbs. However, the decrease was significantly less in the triacsin $\mathrm{C}$ treated animals $(-195 \pm 8.4 \mathrm{nM}$ vehicle vs. $-83 \pm 4.3 \mathrm{nM}$ triacsin $\mathrm{C} ; \mathrm{p}<0.05, \mathrm{n}=5$ animals for each group).

Immediately post-ischemia, the NO signal peaked in both treated and untreated animals. Neither the immediate peak level nor the time-topeak were different between treated and untreated animals. The NO levels declined rapidly in the control animals, at a rate of $14.8 \pm 1.1 \% / \mathrm{min}$, and had returned to baseline within 20 minutes. In contrast, $\mathrm{NO}$ levels declined at $2.1 \pm 0.63 \% / \mathrm{min}$ in triacsin $\mathrm{C}$ treated animals $(\mathrm{p}<0.0001 v s$ control) and reached a plateau level that was maintained for the duration of the experiment.

Figure 3B shows the effect of various NOS inhibitors on post-ischemic intravascular NO synthesis during the final 30 minutes of reperfusion. Pre-treating the animals with LNAME, a non-selective NOS inhibitor, abolished the triacsin $\mathrm{C}$ effect. In contrast, $1400 \mathrm{~W}$, a highly selective iNOS inhibitor, had no effect on NO synthesis during triacsin $\mathrm{C}$ treatment.
Surprisingly, pre-treatment with SMTC, a compound with a 10-fold greater affinity for nNOS as compared to eNOS, virtually abolished the triacsin $\mathrm{C}$ effect.
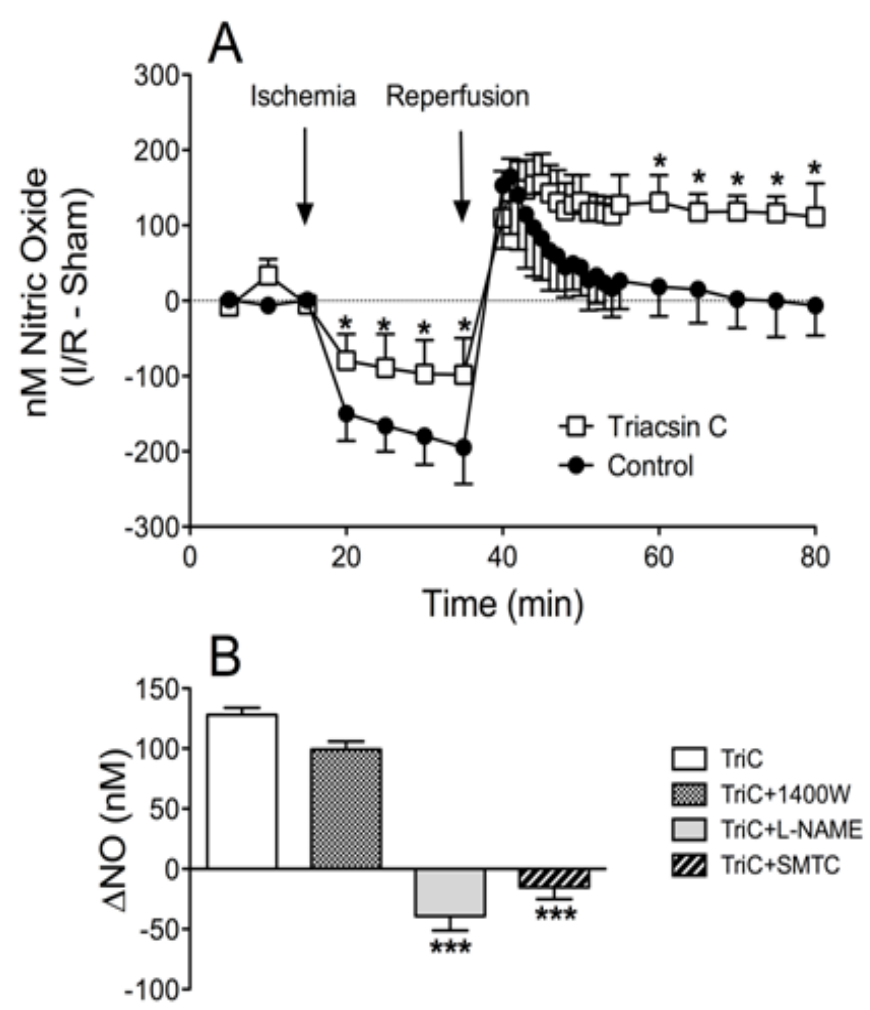

Figure 3. Panel A: Intravascular NO synthesis in the presence and absence of triacsin $\mathrm{C}$ in the perfused hind limb model in the rat. As detailed in Methods, these experiments measured the difference in NO synthesis between normoxic and ischemic limbs. A positive number indicates that the post-ischemic limb is producing more NO than the normoxic limb; a negative number indicates that the normoxic limb is producing more NO than the post-ischemic limb. In the presence of triacsin $\mathrm{C}$, the reperfused ischemic limb produces significantly more NO than the normoxic limb during the ischemic period and during the final 25 minutes of reperfusion. $*=p<0.05$ by 2 -way ANOVA for repeated measures with Bonferroni's post-hoc test; $\mathrm{n}=5$ animals for each group. Panel B: The effect of triacsin $\mathrm{C}$ is abolished by L-NAME and SMTC, not by $1400 \mathrm{~W}$. $* * *=\mathrm{p}<0.0001$ as compared to all other groups, one-way ANOVA; $n=4$ to 8 animals for each group.

Leukocyte recruitment: Leukocyte recruitment was induced in the rat mesentery by superfusion with KHB equilibrated with $95 \%$ 
$\mathrm{N}_{2} / 5 \% \mathrm{CO}_{2}$ containing $50 \mu \mathrm{M}$ L-NAME. These conditions are sufficient to induce a half-maximal increase in leukocyte rolling and surface P-selectin expression [13]. Figure 4 shows the effect of triacsin $\mathrm{C}$ on the time course of L-NAME induced leukocyte rolling, adhesion and extravasation in single post-capillary venules. The baseline values of these parameters were similar for all groups. Compared to baseline, $50 \mu \mathrm{M}$ L-NAME alone significantly increased leukocyte adherence at 60 , 90 and 120 minutes, as well as increased rolling and transmigration at 90 and 120 minutes (all $\mathrm{p}<0.05)$. When $5 \mu \mathrm{M}$ triacsin $\mathrm{C}$ was present in the superfusate, the leukocyte-endothelial interactions were not significantly different from KHB alone. Mean arterial blood pressure (MABP) was maintained in the normal range (i.e., $100 \pm 10 \mathrm{~mm}$ $\mathrm{Hg}$ ) throughout the experiment in all experimental groups.

At the end of the experiment, the superfused mesenteries were fixed and stained with $\mathrm{H} \& \mathrm{E}$ to confirm leukocyte adherence and transmigration. Figure 5 A-C show representative histologic sections of mesenteries. Figure $5 \mathrm{D}$ shows the actual leukocyte counts derived from those sections. As anticipated, superfusion with $50 \mu \mathrm{M}$ L-NAME induced significant leukocyte adhesion and transmigration as compared to KHB alone, an effect that was completely abolished by superfusion when $5 \mu \mathrm{M}$ triacsin $\mathrm{C}$ was included in the superfusate.

\section{Discussion}

The major findings of this study were: 1) In a model of global cardiac ischemia, triacsin $\mathrm{C}$ treatment significantly reduced infarct size and improved post-ischemic inotropic (LVDP, $\left.\mathrm{dP} / \mathrm{dt}_{\max }\right)$ and lusitropic $\left(\mathrm{dP} / \mathrm{dt}_{\min }\right)$ performance; 2$)$ The cardioprotective effects of triacsin $\mathrm{C}$ were blocked by L-NAME, a non-selective NOS inhibitor; 3) Triacsin C significantly increased intravascular NO concentration during ischemia and reperfusion and these effects were attenuated by L-NAME and SMTC, a selective nNOS inhibitor; 4) Triacsin $\mathrm{C}$ inhibited the leukocyteendothelial interactions required for leukocyte recruitment.
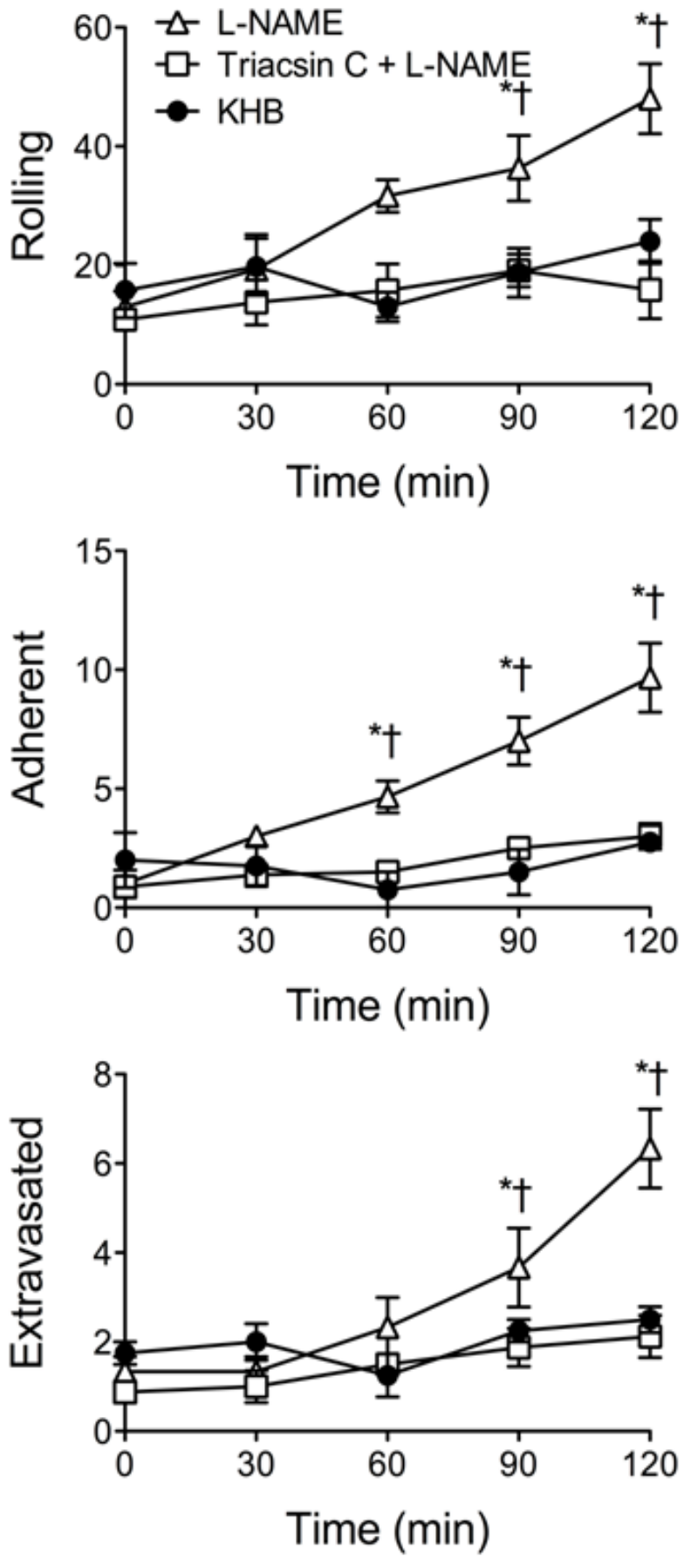

Figure 4. The effect of triacsin $\mathrm{C}$ on L-NAME induced leukocyte recruitment in single post-capillary venules of the rat mesenteric vasculature, as described in Methods. In the presence of triacsin C, L-NAME induced rolling (Panel A), adhesion (Panel B) and extravasation (Panel C) of leukocytes were significantly inhibited. Results were analyzed by twoway ANOVA. $*=p<0.05$ as compared to triacsin $\mathrm{C}$ 
treated; $\uparrow=p<0.05$ as compared to $t_{0} ; n=4$ animals in each group.

The infarct zone in the control hearts was a continuous band of sub-epicardial tissue, consistent with the observation of others that the sub-epicardium/mid-myocardium is more vulnerable to $\mathrm{I} / \mathrm{R}$ insults than the endocardium [41]. Triacsin $\mathrm{C}$ treatment during the first five minutes of reperfusion reduced the infarct size by about $50 \%$ as compared to untreated hearts. While the infarcted tissue was still sub-epicardial in the treated hearts, the infarct zone was discontinuous, suggesting improved sub-epicardial flow on reperfusion.
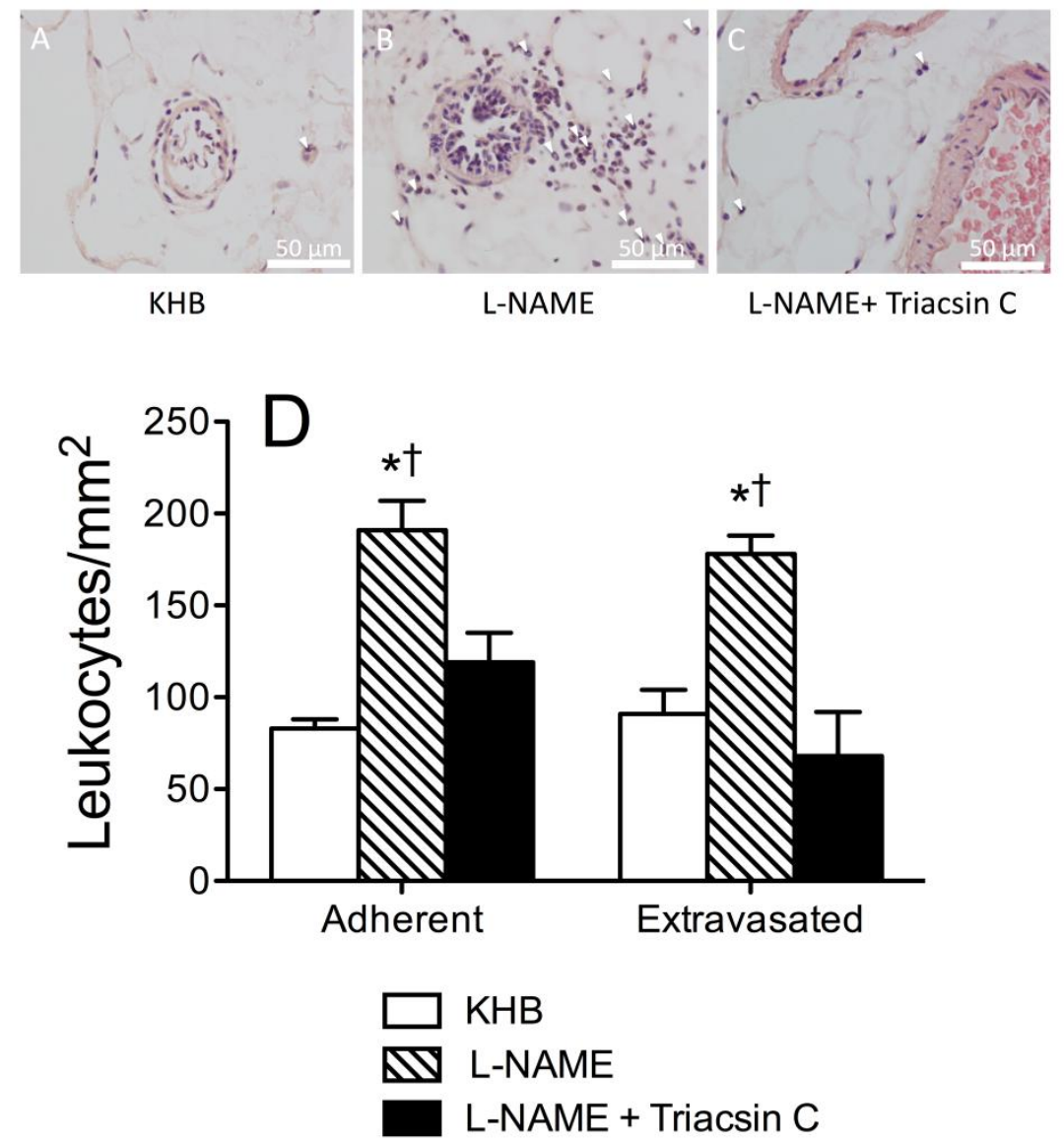

Figure 5. Panels A, B and C: Representative H\&E staining of rat mesentery superfused with normoxic KHB (Panel A), KHB containing $50 \mu \mathrm{M}$ L-NAME (Panel B) or containing $50 \mu \mathrm{M}$ L-NAME plus $5 \mu \mathrm{M}$ triacsin C (Panel C). Triacsin $\mathrm{C}$ significantly decreased L-NAME induced adhesion and extravasation of leukocytes (indicated by arrows); 40X magnification. Panel D: cell counts; $*=p<0.05$ as compared to normoxic KHB alone; $\dagger=p<0.05$ as compared to Triacsin C plus L-NAME. Adherent and extravasated leukocytes were analyzed by one way ANOVA.

The coronary flow data show no significant differences between control and triacsin $\mathrm{C}$ treated hearts. However, in our system, the flow probe is placed in the perfusion line, and not in the coronary vasculature itself. Thus, while our data provide an accurate estimate of total coronary flow, it provides no information about the transmural flow distribution, a factor directly relevant to infarct development [41].
As expected, cardiac function was compromised in all hearts during reperfusion. However, recovery of function paralleled preservation of viable tissue. Thus, treatment with triacsin $\mathrm{C}$ for the first 5 minutes of reperfusion resulted in functional recovery that was nearly twice as great as the untreated controls. The triacsin $\mathrm{C}$ effect was abolished by concurrent treatment with L-NAME, suggesting that the 
preservation of function is mediated by increased NO synthesis and/or bioavailability.

The relationship between NO availability and $\mathrm{I} / \mathrm{R}$ injury is complex. In the heart, constiuitive leevels of NO derived from eNOS are beneficial [42]. Myocardial infarct size is larger in eNOS knock-out mice suggesting that preservation of eNOS function is protective in $\mathrm{I} / \mathrm{R}$ injury [43]. This earlier work is reinforced by the more recent findings that eNOS gene transfer at the time of reperfusion reduces the infarct volume [44] and that experimental manipulations that increase eNOS activity by phosphorylation at Ser(1179) and $\operatorname{Ser}(635)$ increase eNOS activity and are cardioprotective [45].

While it would be interesting to study the effect of triacsin $\mathrm{C}$ treatment on NO synthesis in the heart, anatomic reality precludes placing NO probes in the coronary vasculature. Hence, we turned to the ischemic hind limb model to measure the effect of triacsin $\mathrm{C}$ treatment on intravascular NO synthesis in situ. In this study, intravascular NO concentrations both during and after ischemia were significantly greater in triacsin $\mathrm{C}$ treated animals. While similar peak reperfusion levels were reached in both treated and untreated animals, the effect persisted for at least 45 minutes in the traicsin $\mathrm{C}$ treated animals.

As anticipated, the triacsin $\mathrm{C}$ effect was abolished by L-NAME and was unaffected by 1400W. The effect of SMTC, an inhibitor with about 10 fold greater affinity for nNOS than for eNOS, to significantly reduce the triacsin $\mathrm{C}$ effect was unexpected. These data suggest that it is possible that at least part of the increase in postischemic intravascular $\mathrm{NO}$ in the presence of triacsin $\mathrm{C}$ is a consequence of nNOS activation. nNOS has been identified in human coronary vascular smooth muscle [46] but its role in cardiac $\mathrm{I} / \mathrm{R}$ injury is poorly understood. Data from other labs is contradictory; nNOS knock-out mice showed reduced incidence of post-reperfusion arrythmias and increased survival rates as compared to controls [17], but impaired cardioprotection from ischemic pre-conditioning [47]. In human studies, it has been reported that basal microvascular tone is tonically regulated by nNOS, independent of eNOS, in both the forearm and coronary vasculature [48].
Our data showing that triacsin $\mathrm{C}$ inhibits leukocyte recruitment could be explained by invoking increased NOS activity. However, the concentration of L-NAME that reversed the effect of triacsin $\mathrm{C}$ on cardiac performance and infarct size was the same concentration used to initiate leukocyte-endothelial interactions, and that those interactions were reversed by triacsin $\mathrm{C}$. Thus, increased eNOS activity may not be the sole mechanism by which triacsin $\mathrm{C}$ inhibits leukocyte recruitment. Since triacsin C inhibits eNOS palmitoylation [34], it is tempting to speculate that triacsin $\mathrm{C}$ may inhibit palmitoylation of additional proteins, thus changing their function and/or subcellular location.

Protein palmitoylation is a very rapid (halftime of seconds) common pathway facilitating protein trafficking $[49,50]$. Indeed, proteins that are rapidly re-partitioned between cytoplasm and membrane are suspects for palmitoylation [50]. Proteins such as platelet endothelial cellular adhesion molecule (PECAM) [51] and P-selectin [52], which are translocated to the plasma membrane early in the ischemic injury cascade, require palmitoylation for activation or localization.

Interestingly, PECAM knockout mice have been reported to have higher basal eNOS activity and NO availability [53]. The subcellular localization of at least one other protein regulator of both NOS, heme oxygenase-1, is palmitoylation dependent [54]. This finding is particularly interesting because heme oxygenase-1 regulates eNOS function [55], its upregulation abrogates myocardial I/R injury [56-58] and gene therapy with heme oxygenase-1 has long-lasting cardioprotective effects [45].

Thus, inhibiting FACS appears to target simultaneously multiple points in the ischemic injury cascade. The present study provides evidence that triacsin $\mathrm{C}$ reduces infarct size associated with global cardiac I/R, attenuates the loss of post-reperfusion cardiac function, and increases intravascular NO concentration. Furthermore, by inhibiting leukocyte-endothelial interactions, triacsin $\mathrm{C}$ may attenuate the vascular inflammatory component associated with $\mathrm{I} / \mathrm{R}$ injury [4]. These findings suggest that triacsin $C$, in conjunction with current therapies, may be 
useful in treating myocardial infarction.

\section{References}

1. Roger, V.L.; Go, A.; Lloyd-Jones, D.M. The American Heart Association Statistics Committee and Stroke Statistics Subcommittee. Heart Disease and Stroke Statistics - 2011 Update: A report from the American Heart Association, Circulation, 2011, 123, e18-e209. DOI: 10.1161/CIR.0b013e3182009701

2. Virdis, A.; Ghiadoni, L.; Giannarelli, C.; Taddei, S. Endothelial dysfunction and vascular disease in later life. Maturitas, 2010, 67, 20-24. DOI: 10.1016/j.maturitas.2010.04.006

3. Tsao, P.S.; Ma, X.L.; Lefer, A.M. Activated neutrophils aggravate endothelial dysfunction after reperfusion of the ischemic feline myocardium. Am Heart J, 1992, 123, 14641471. DOI: $10.1016 / 0002-8703(92) 90796-X$

4. Lefer, A.M.; Lefer, D.J. The role of nitric oxide and cell adhesion molecules on the microcirculation in ischaemia-reperfusion. Cardiovasc Res; 1996, 32,74-7513. DOI: 10.1016/S0008-6363(96)00073

5. Lucchesi B.; Mullane K. Leukocytes and ischemia-induced myocardial injury. Annu Rev Pharmacol Toxicol, 1986, 26,2011-2024. DOI: 10.1146/annurev.pa.26.040186.001221

6. Burke-Gaffney, A.; Hellewell, P.G. Tumour necrosis factor-alpha induced ICAM-1 expression in human vascular endothelial and lung epithelial cells: modulation by tyrosine kinase inhibitors, Br J Pharmacol, 1996, 119, 1149-1158.

7. Zhang, XW.; Liu, Q.; Wang, Y.; Thorlacius, $\mathrm{H}$. CXC chemokines, MIP-2 and KC, induce $\mathrm{P}$-selectin-dependent neutrophil rolling and extravascular migration in vivo, $\mathrm{Br} J$ Pharmacol, 2001, 133, 413-421. DOI: 10.1038/sj.bjp.07040 b b bb bnhn87

8. Entman, M.; Smith, W. Postreperfusion inflammation: a model for reaction to injury in cardiovascular disease, Cardiovascular Research, 1994, 28, 1301-1311. DOI: $10.1093 / \mathrm{cvr} / 28.9 .1301$
9. Dull, G.N.; Randal, G.N.; Garcia, G.N. Leukocyte-induced microvascular permeability: how contractile tweaks lead to leaks, Circulation Research, 2002, 90, 11431144. DOI:

$\underline{10.1161 /}$ 01.RES.0000023047.87638.76

10. Cai, H.; Harrison D.G. Endothelial dysfunction in cardiovascular diseases: the role of oxidant stress. Circ Res, 2000, 87,840844. DOI: $10.1161 / 01 . R E S .87 .10 .840$

11. Schafer, A.; Bauersachs J. Endothelial dysfunction, impaired endogenous platelet inhibition and platelet activation in diabetes and atherosclerosis. Curr Vasc Pharmacol, 2008, 6, 52-60. DOI: $\underline{10.2174 / 157016108783331295}$

12. Gkaliagkousi, E.; Douma S.; Zamboulis C.; Ferro A. Nitric oxide dysfunction in vascular endothelium and platelets: role in essential hypertension. J Hypertens, 2009, 27, 23102320.

DOI: 10.1097/HJH.06013e328330e89a

13. Davenpeck, K.L.; Gauthier, T.W.; Lefer, A.M. Inhibition of endothelial-derived nitric oxide promotes P-selectin expression and actions in the rat microcirculation. Gastroenterology. 1994; 107, 1050-8.

14. Chen, Q.; Rueter B. M.; Krass S.; Zambrano C.; Thomas S.; Prince C.; Bell B.; Chai V.; Emrich J.; Young L.H. The potential clinical application of protein kinase $\mathrm{C}$ beta II peptide inhibitor or Gö 6983 in vascular endothelial dysfunction. Current Topics in Pharmacology, 2010a, 14, 11-24.

15. Li, J.; Wu, F.; Zhang, H.; Fu, F.; Ji, L.; Dong, L.; Li, Q.; Liu, W.; Zhang, Y.; Lv, A.; Wang, H.; Ren, J.; Gao, F. Insulin inhibits leukocyte-endothelium adherence via an AktNO-dependent mechanism in myocardial ischemia/reperfusion. Journal of Molecular and Cellular Cardiology, 2009, 47, 512-519. DOI: $10.1016 /$ j.yjmcc.2009.07.010

16. Kakkar, A.K.; Lefer, D.J. Leukocyte and endothelial adhesion molecule studies in knockout mice, Curr Opin Pharmacol, 2004, 4, 154-158. DOI: 10.1016/j.coph.2004.01.003

17. Burger, D.E.; Lu, X.; Lei, M.; Xiang, F.L.; Hammoud, L.; Jiang, M.; Wang, H.; Jones, 
D.L.; Sims, S.M.; Feng, Q. Neuronal nitric oxide synthase protects against myocardial infarction-induced ventricular arrhythmia and mortality in mice, Circulation, 2009, 120, 1345-1354. DOI: $\quad \underline{10.1161 /}$ CIRCULATIONAHA.108.846402

18. Icking, A.; Matt, S.; Opitz, N.; Wiesenthal, A.; Müller-Esterl, W.; Schilling, K. NOSTRIN functions as a homotrimeric adaptor protein facilitating internalization of eNOS, J Cell Sci, 2005, 118, 5059-5069. DOI: $10.1242 / \mathrm{jcs} .02620$

19. Dedio, J.; König, P.; Wohlfart, P.; Schroeder, C.; Kummer, W.; Müller-Esterl, W. NOSIP, a novel modulator of endothelial nitric oxide synthase activity, FASEB J, 2001, 15, 79-89. DOI: $10.1096 / \mathrm{fj} .00-0078 \mathrm{com}$

20. König, P.; Dedio, J.; Müller-Esterl, W.; Kummer, W. Distribution of the novel eNOSinteracting protein NOSIP in the liver, pancreas, and gastrointestinal tract of the rat, Gastroenterology, 2002, 123, 314-324. DOI: 10.1053/gast.2002.34212

21. König, P.; Dedio, J.; Oess, S.; Papadakis, T.; Fischer, A.; Müller-Esterl, W.; Kummer, W. NOSIP and its interacting protein, eNOS, in the rat trachea and lung, $J$ Histochem Cytochem, 2005, 53, 155-64. DOI: 10.1369/jhc.4A6453.2005

22. Csiszar, A.; Ungvari, Z.; Koller, A.; Edwards, J.G.; Kaley, G. Aging-induced phenotypic changes and oxidative stress impair coronary arteriolar function, Circ Res, 2002, 90, 1159$1166 . \quad$ DOI: $\underline{10.1161 /}$ 01.RES.0000020401.61826.EA

23. Pritchard, K.A. Jr.; Ackerman, A.W.; Gross, E.R.; Stepp, D.W.; Shi, Y.; Fontana, J.T.; Baker, J.E.; Sessa, W.C. Heat shock protein 90 mediates the balance of nitric oxide and superoxide anion from endothelial nitricoxide synthase, J Biol Chem, 2001, 276, 17621-17624.

DOI: 10.1074/jbc.C100084200

24. Feron, O.; Saldana, F.; Michel, J.B.; Michel, T. The endothelial nitric-oxide synthasecaveolin regulatory cycle, J Biol Chem, 1998, 273, 3125-3128. DOI: $\underline{10.1074 / \mathrm{jbc} .273 .6 .3125}$
25. Bauer, P.M.; Fulton, D. Compensatory phosphorylation and protein-protein interactions revealed by loss of function and gain of function mutants of multiple serine phosphorylation sites in endothelial nitricoxide synthase, J Biol Chem, 2003, 278, 14841-9. DOI: $10.1074 /$ jbc.M211926200

26. Church, J.E.; Fulton, D. Differences in eNOS activity because of subcellular localization are dictated by phosphorylation state rather than the local calcium environment, $J$ Biol Chem, 2006, 281, 1477-1488. DOI: 10.1074/jbc.M505968200

27. Ju, H.; Zou, R.; Venema, J.; Venema, R.C. Direct interaction of endothelial nitric-oxide synthase and caveolin-1 inhibits synthase activity, J Biol Chem, 1997, 272, 1852218525. DOI: $10.1074 / \mathrm{jbc} .272 .30 .18522$

28. Feron, O.; Michel, J.; Sase, K.; Michel, T. Dynamic regulation of endothelial nitric oxide synthase; complementary roles of dual acylation and caveolin interaction, Biochemistry, 1998b, 37, 193-200. DOI: 10.1021/bi972307p

29. Robinson, L.G.; Michel, T. Mutagenesis of palmitoylation sites in endothelial nitric oxide synthase identifies a novel motif for dual acylation and subcellular targeting, Proc Nat Acad Sci U.S.A., 1995, 92, 11776-11780.

30. Liu, J.; Hughes, T.E.; Sessa, W.C. The first 35 amino acids and fatty acylation sites determine the molecular targeting of endothelial nitric oxide synthase into the Golgi region of cells: a green fluorescent protein study, J Cell Biol, 1997, 277, 3303233040.

31. Garcia-Cardeñas, G.; Martesek, P.; Masters, B.S.; Skidd, P.M.; Couet, J.; Li, S.; Lisanti, M.P.; Sessa, W.C. Dissecting the interaction between nitric oxide synthase and caveolin, $J$ Biol Chem, 1997, 272, 25437-25440. DOI: 10.1074/jbc.272.41.25437

32. Michel, J.B.; Feron, O.; Sase, K.; Prabhakar, P.; Michel, T. Caveolin versus calmodulincounterbalancing allosteric modulators of endothelial nitric oxide synthase, $J$ Biol Chem, 1997, 272, 25907-25912. DOI: $\underline{10.1074 / \mathrm{jbc} .272 .41 .25907}$ 
33. Yoshida, K.; Okamoto, M.; Umehara, K.; Iwami, M.; Kohsaka, M.; Aoki, H.; Imanaka, H. Studies on new vasodilators, WS-1228A and B. Discovery, taxonomy, isolation and characterization, J Antibiot, 1982, 35, 151156. DOI: 10.7164 /antibiotics.35.151

34. Weis, M.T.; Crumley, J.; Young, L.H.; Stallone, J.N. Inhibiting long chain fatty acyl CoA synthetase increases basal and agoniststimulated NO synthesis in endothelium, Cardiovasc Res, 2004, 63, 338-346. DOI: 10.1016/j.cardiores.2004.04.025

35. Weis, M.T.; Brady, M.; Moore, M.; Crumley, J.; Stallone, J.N. Inhibiting long-chain fatty acyl CoA synthetase does not increase agonist induced release of arachidonate metabolites from human endothelial cells, J Vasc Res, 2005, 42, 275-283. DOI: $10.1159 / 000085847$

36. Peterman, E.E.; Taormina, P. II; Harvey, M.; Young, L.H. Gö 6983 exerts cardioprotective effects in mycoardial ischemia/reperfusion. $J$. Cardiovasc. Pharmacol, 2004, 43:645-656.

37. Chen, Q.; Kim, E.J.; Elio, K.; Zambrano, C.; Krass, S.; Teng, J.; Kay, H.; Perkins, K.A.; Pershad S.; McGraw, S.; Emrich J.; Adams, J.S.; Young, L.H. The role of Tetrahydrobiopterin $\quad\left(\mathrm{BH}_{4}\right) \quad$ and Dihydrobiopterin $\left(\mathrm{BH}_{2}\right)$ in ischemia/reperfusion (I/R) injury when given at reperfusion. Advances in Phamacological Sciences 2010b, Artical ID 963914. DOI: 10.1155/2010/963914

38. Young, L. H.; Chen, Q.; Weis, M.T. Direct Measurement of Hydrogen Peroxide $\left(\mathrm{H}_{2} \mathrm{O}_{2}\right)$ or Nitric Oxide (NO) Release A powerful Tool to Assess Real-time Free Radical Production in Biological Models. Am $J$. Biomed. Sci. 2011, 3, 40-48. DOI: 10.5099/aj110100040

39. Perkins, K.A.; Pershad, S.; Chen, Q.; McGraw, S.; Adams, J.S.; Zambrano, C.; Krass, S.; Emrich, J.; Bell, B.; Iyamu, M.; Prince, C.; Kay, H.; Teng, J.C.; Young, L.H. The effects of modulating eNOS activity and coupling in ischemia/reperfusion (I/R). Naunyn-Schmiedeberg's Archives of Pharmacology 2012, 385, 27-38. DOI: 10.1007/s00210-011-0693-Z
40. Zhang, X. Electro-chemical sensors, biosensors and their biomedical applications. Ed.; Elsevier, 2008; pp1-55.

41. Leshnower, B.G.; Sakamoto, H.; Hamamoto, H.; Zeeshan, A.; Gorman, J. H. III; Gorman, R.C. Progression of Myocardial Injury During Coronary Occlusion in the CollateralDeficient Heart: A Non-wavefront Phenomenon. Am. J Physiol Heart Cir, 2007, 293, 1799-1804. DOI: 10.1152/ajpheart. $\underline{00590.2007}$

42. Jugdutt, B.I. Nitric oxide and cardioprotection during ischemia-reperfusion, Heart Fail Rev, 2002, 7, 391-405. DOI: 10.1023/A:1020718619155

43. Sumeray, M.S.; Rees, D.D.; Yellon, D.M. Infarct size and nitric oxide synthase in murine myocardium, J Mol Cell Cardiol., 2000, 32, 35-42. DOI: 10.1006/jmcc.1999.1050

44. Szelid, Z.; Pokreisz, P.; Liu, X.; Vermeersch, P.; Marsboom, G.; Gillijns, H.; Pellens, M.; Verbeken, E.; Van de Werf, F.; Collen, D.; Janssens, S.P. Cardioselective nitric oxide synthase 3 gene transfer protects against myocardial reperfusion injury, Basic Res Cardiol, 2010, 105, 169-179. DOI: 10.1007/s00395-009-0077-4

45. Li, Q.; Guo, Y.; Ou, Q.; Wu, W.J.; Chen, N.; Zhu, X.; Tan, W.; Yuan, F.; Dawn, B.; Luo, L.; Hunt, G.N.; Bolli, R. Gene transfer as a strategy to achieve permanent cardioprotection II: rAAV-mediated gene therapy with heme oxygenase- 1 limits infarct size 1 year later without adverse functional consequences, Basic Res Cardiol, 2011, 106, 1367-1377. DOI: $10.1007 / \mathrm{s} 00395-011-$ $\underline{0208-6}$

46. Han, G.; Ma, H.; Chintala, R.; Miyake, K.; Fulton, D.J.; Barman, S.A. White RE. Nongenomic, endothelium-independent effects of estrogen on human coronary smooth muscle are mediated by type I (neuronal) NOS and PI3-kinase-Akt signaling, Am J Physiol Heart Circ Physiol, 2007, 293, H314321. DOI: 10.1152/ajpheart.01342.2006 
47. Lu, X.M.; Zhang, G.X.; Yu, YQ.; Kimura, S.; Nishiyama, A.; Matsuyoshi, H.; Shimizu, J.;

Takaki. M. The opposite roles of nNOS in cardiac ischemia-reperfusion-induced injury and in ischemia preconditioning-induced cardioprotection in mice, J Physiol Sci, 2009, 59, 253-262. DOI: $10.1007 / \mathrm{s} 12576-009-$ $\underline{0030-1}$

48. Seddon, M.; Melikian, N.; Dworakowski, R.; Shabeeh, H.; Jiang, B.; Byrne, J.; Casadei, B.; Chowienczyk, P.; Shah, A.M. Effects of neuronal nitric oxide synthase on human coronary artery diameter and blood flow in vivo, Circulation, 2009, 119, 2656-2662.

DOI: $\underline{10.1161 /}$ CIRCULATIONAHA.108.822205

49. Greaves, J.; Chamberlain, L.H. Palmitoylation-dependent protein sorting, $J$ Cell Biol, 2007, 176, 249-254. DOI: 10.1083/jcb.200610151

50. Rocks, O.; Gerauer, M. Vartak, N.; Koch, S.; Huang, Z.P.; Pechlivanis, M.; Kuhlmann, J.; Brunsveld, L.; Chandra, A.; Ellinger, B.; Waldmann, H.; Bastiaens, P.I. The palmitoylation machinery is a spatially organizing system for peripheral membrane proteins, Cell, 2010, 141, 458-471. DOI: 10.1016/j.cell.2010.04.007

51. Sardjono, C.T.; Harbour, S.N.; Yip, J.C.; Paddock, C.; Tridandapani, S.; Newman, PJ.; Jackson, D.E. Palmitoylation at Cys595 is essential for PECAM-1 localisation into membrane microdomains and for efficient PECAM-1-mediated cytoprotection, Thromb Haemost, 2006, 96, 756-766. DOI: 10.1160/TH06-08-0459

52. Sim, D.S.; Dilks, J.R.; Flaumenhaft, R. Platelets possess and require an active protein palmitoylation pathway for agonist-mediated activation and in vivo thrombus formation, Arterioscler Thromb Vasc Biol, 2007, 27, 1478-1485. DOI: $\underline{10.1161 /}$ ATVBAHA.106.139287
53. McCormick, M.E.; Goel, R.; Fulton, D.; Oess, S.; Newman, D.; Tzima, E. Plateletendothelial cell adhesion molecule-1 regulates endothelial NO synthase activity and localization through signal transducers and activators of transcription 3-dependent NOSTRIN expression, Arterioscler Thromb Vasc Biol, 2011, 31, 643-649. DOI: 10.1161/ ATVBAHA.110.216200

54. Lynes, E.M.; Bui, M.; Yap, M.C.; Benson, M.D.; Schneider, B.; Ellgaard, L.; Berthiaume, L.G.; Simmen, T. Palmitoylated TMX and calnexin target to the mitochondriaassociated membrane, EMBO J, 2011, 31, 457-470. DOI: 10.1038/emboj.2011.384

55. Polizio, A.H.; Santa-Cruz, D.M.; Balestrasse, K.B.; Gironacci, M.M.; Bertera, F.M.; Höcht, C.; Taira, C.A.; Tomaro, M.L.; Gorzalczany, S.B. Heme oxygenase-1 overexpression fails to attenuate hypertension when the nitric oxide synthase system is not fully operative, Pharmacology, 2011, 87, 341-349. DOI: $\underline{10.1159 / 000327939}$

56. Novo, G.; Cappello, F.; Rizzo, M.; Fazio, G.; Zambuto, S.; Tortorici, E.; Gammazza, A.M.; Corrao, S.; Zummo, G.; De Macario, E.C.; Macario A.J.; Assennato, P.; Novo, S.; Li Volti, G. Hsp60 and heme oxygenase-1 (Hsp32) in acute myocardial infarction, Transl Res, 2011, 157, 285-292. DOI: 10.1016/j.trsl.2011.01.003

57. Wu, M.L.; Ho, Y.C.; Lin, C.Y.; Yet, S.F. Heme oxygenase-1 in inflammation and cardiovascular disease, Am J Cardiovasc Dis, 2011, 1, 150-158.

58. Lakkisto, P.; Siren, J.M.; Kytö, V.; Forsten, H.; Laine, M.; Pulkki, K.; Tikkanen, I. Heme oxygenase-1 induction protects the heart and modulates cellular and extracellular remodelling after myocardial infarction in rats, Exp Biol Med (Maywood), 2011, 236, 1437-1448. DOI: 10.1258/ebm.2011.011148 